\title{
A method to assess the relative contribution of lateral inhibition to the magnitude of visual-geometric illusions
}

\author{
STANLEY COREN \\ University of British Columbia, Vancouver, British Columbia, Canada \\ CLARE PORAC \\ University of Victoria, Victoria, British Columbia, Canada \\ DEBORAH J. AKS \\ University of British Columbia, Vancouver, British Columbia, Canada \\ and \\ KAZUNORI MORIKAWA \\ University of Tokyo, Hongo, Tokyo, Japan
}

\begin{abstract}
Observer errors of judged length when viewing the Müller-Lyer illusion arise partially from distortions caused by lateral neural interactions in the retina. To assess the relative contribution of such lateral neural interactions to the total magnitude of the illusion, the Müller-Lyer figure was presented to observers under a form of intermittent-light stimulation that enhances lateral inhibitory activity. In Experiment 1, intermittent-light conditions produced the largest increase in illusion strength for the standard variant of the Müller-Lyer figure but not for a dot form in which contour interactions are minimized. The results of Experiment 2 showed that the hypothesized lateral inhibitory contribution varied as a function of wing-shaft angle. In addition to confirming the contribution of lateral neural interactions to illusion formation, these findings also suggest that exposure of illusion configurations under intermittent illumination may provide a method of determining the relative contribution of lateral inhibition to illusion configurations other than the Müller-Lyer.
\end{abstract}

Systematic distortions in the apparent shape, size, and direction of pattern elements are known as visualgeometric illusions. Over the last 20 years, research has demonstrated convincingly that these illusions are the perceptual result of a number of distortion-producing mechanisms operating at different levels in the visual system (see Coren \& Girgus, 1978a, 1978b; Coren \& Ward, 1979; Uttal, 1981). Conceptually, we can distinguish two general classes of illusion-producing mechanisms. The first category contains a number of cognitive and judgmental processing mechanisms that contribute to the perceptual error; the second group of mechanisms is structural in nature, associated with optical and neural interactions in the visual system which distort certain dimensions in the final percept.

The cognitive contributions to visual illusions are judgmental errors based on the information-processing strategies, or assumptions and biases employed when visual

\footnotetext{
This research was supported by grants from the Natural Sciences and Engineering Research Council of Canada. We acknowledge the contribution of Wayne Wong, who assisted in the organization of the data collection, and Susan Dumais, who collected the pilot data for Experiment 3. Address reprint requests to Stanley Coren, Department of Psychology, University of British Columbia, Vancouver, BC, Canada, V6T IW5.
}

stimuli are viewed (see Coren \& Girgus, 1978a, for a review). These strategies include confusion between the figural elements that contribute to the distortions (Coren \& Girgus, 1972; Erlebacher \& Sekuler, 1969), application of three-dimensional processing to two-dimensional arrays (Coren \& Girgus, 1977; Gillam, 1971, 1980; Gregory, 1968; Ward, Porac, Coren, \& Girgus, 1977; Warren \& Bashford, 1977), averaging and/or contrast among figural elements (Coren \& Miller, 1974; Girgus \& Coren, 1982; Jordon \& Uhlarik, 1986; Massaro \& Anderson, 1971; Pressey, 1974; Restle \& Decker, 1977), distribution of attention over the illusion figure (Coren \& Porac, 1983; Goryo, Robinson, \& Wilson, 1984), and implicit biases used to extract eye-movement information (Coren, 1986).

A number of structural factors that contribute to the formation of visual illusions have also been isolated. Estimates of the contribution of these structural factors to the final illusion strength vary from values as high as $40 \%$ to $47 \%$ (Coren, 1970a, 1970b; Coren \& Porac, 1984) to values as low as $12 \%$ to $16 \%$ (Gillam \& Chambers, 1985; Mack, Heuer, Villardi, \& Chambers, 1985). These structural factors include the blurring of the retinal image due to optical aberrations in the crystalline lens or because of light scatter within the optic globe, or the neural equiva- 
lent of blur due to the limited spatial-frequency response of the eye. These factors have been shown to contribute to the magnitude of intersecting-line illusions, such as those of the Müller-Lyer and Poggendorf figures (Coren, 1969; Coren \& Porac, 1978; Coren, Ward, Porac, \& Fraser, 1978; Ward \& Coren, 1976).

In addition to the optical factors, there are also specific patterns of neural interaction that cause contour attraction or repulsion, which also seem to contribute to various illusions (Coren \& Girgus, 1978a, 1978b; Weintraub $\&$ Schneck, 1986). These neural interactions are of a retinal locus and appear to operate through lateral inhibitory processes (Coren, 1970a; Coren \& Girgus, 1978a; Wallace, 1975; Wenderoth, Beh, \& White, 1978). It should be recognized, however, that similar effects have been postulated to occur at the cortical level because of interactions between populations of orientation-specific receptors (Carpenter \& Blakemore, 1973). Lateral inhibitory interactions have been implicated as contributing over $20 \%$ of the distortion observed in some intersecting-line illusions (see, e.g., Coren \& Girgus, 1978a, 1978b). Specifically, this mechanism operates by distorting the shape of acute angles, which may, in turn, produce distortions in the apparent shape or size of some elements of the array. Ridges of neural activity corresponding to contours imaged on the retina summate when the contours are spatially proximate and repulse each other when the contours are at an intermediate distance. This process distorts the neural correlate of an angle, as shown in Figure 1A (dotted lines), displacing the apparent vertex into the body of the angle. Figures $1 \mathrm{~B}$ and $1 \mathrm{C}$ show the pattern of neural interactions responsible for this angular distortion. When contours are close, their corresponding excitatory maxima summate to cause contour merging or attraction (Figure 1B); at intermediate distances, the inhibitory flanks overlap the excitatory centers asymmetrically, causing apparent contour repulsion (Figure 1C). Figure 2 demonstrates this process in the context of the MüllerLyer illusion and shows how this distortion in angle shape can result in a distortion of apparent length (see also Coren \& Girgus, 1978a; Coren, Porac, \& Ward, 1984). Similar models can be constructed using a cortical, rather than a retinal, locus for such lateral inhibitory interactions (Wenderoth, O'Connor, \& Johnson, 1986).

Because a number of processes contribute to a visual illusion, many studies have attempted to quantitatively determine the contribution of various mechanisms to the final illusory percept. Illusion decrement (the decrease in illusion magnitude that occurs when viewing an illusion figure with free eye movements) is one method used to determine the relative role of structural versus cognitivestrategy components in illusion formation. Decrement is assumed to represent changes in the cognitive components of the illusion, since a few minutes of inspection should not alter the patterns of optical and retinal neural interactions significantly (see Coren \& Girgus, 1978a, 1978b for reviews). This assumption is made more tenable by data suggesting that fatigue of orientation-specific cortical neurons does not play a role in decrement (Coren,
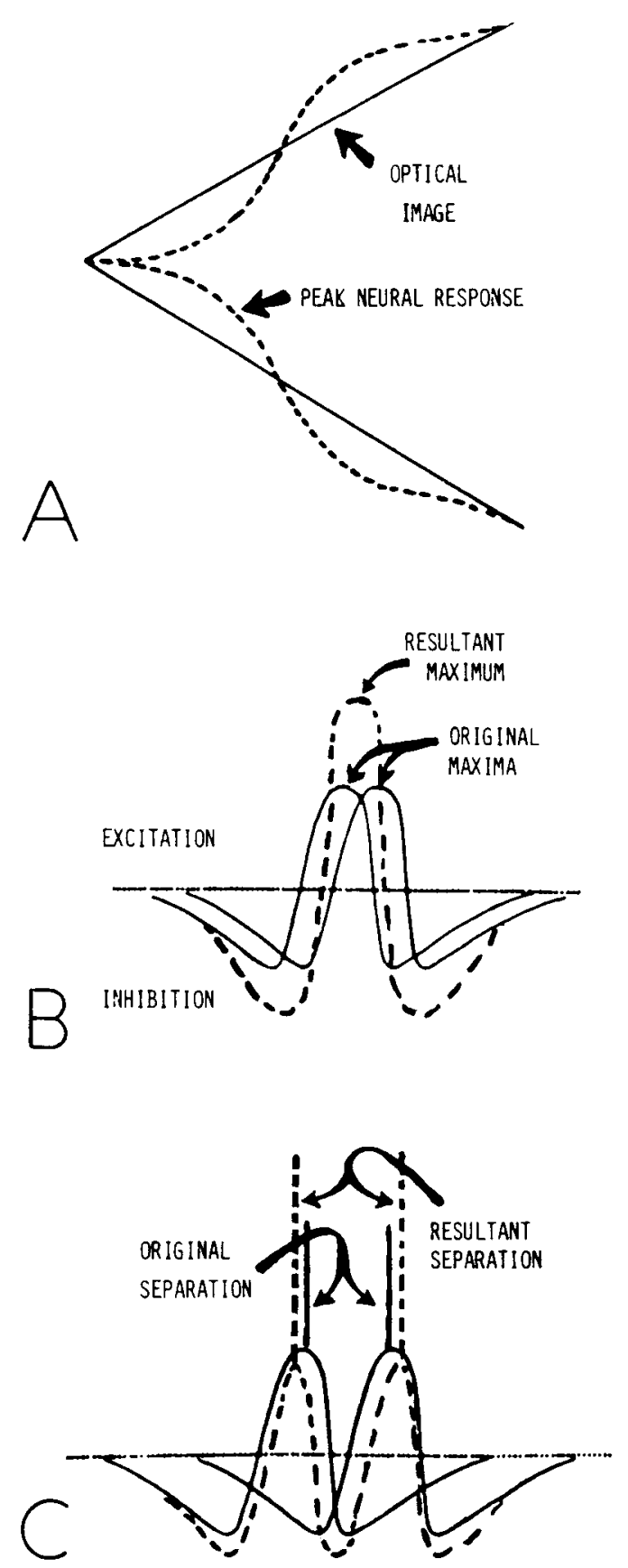

Figure 1: (A) The dotted line shows the expected ridge of peak neural activity when the retinal image is the angle depicted as solid lines. This pattern of neural response arises from the attraction of neural activity when contours are close $(B)$ and the repulsion when contours are at an intermediate distance (C).

Girgus, \& Schiano, 1986). Data from decrement studies indicate that as much as $40 \%$ to $50 \%$ of the magnitude of some intersecting-line illusions is the result of unchangeable structural mechanisms (Coren \& Girgus, 1978a; Coren \& Porac, 1984).

Researchers who have attempted to isolate the specific contribution of lateral inhibition have used other tech- 


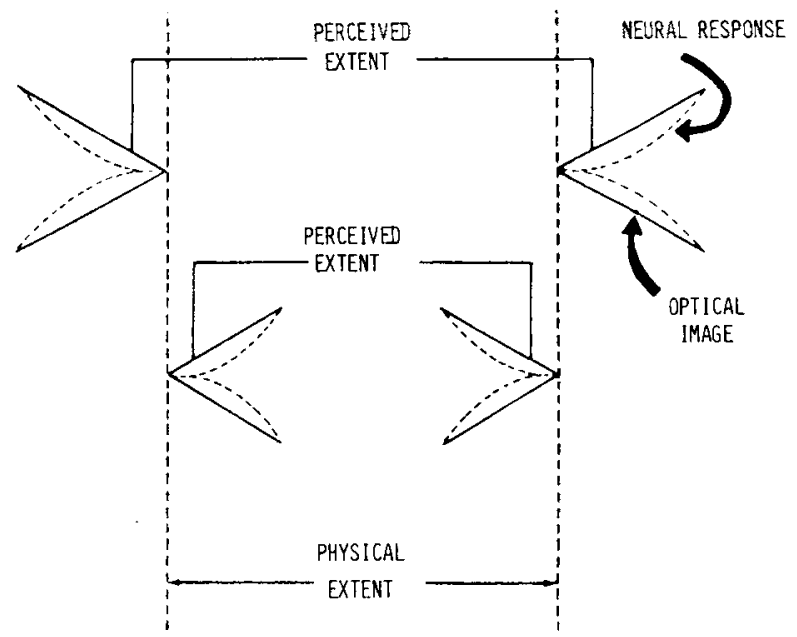

Figure 2. The pattern of neural responses shown in Figure 1 can lead to the distortion of the apparent distance between the angle vertexes in the Müller-Lyer illusion.

niques. Since the illusion component attributed to the operation of an inhibitory mechanism requires the presence of converging or intersecting line images on the retina, one can modify the configuration to eliminate such stimulus components and, as a consequence, eliminate the role of lateral inhibition. Figures without lines, where dots demarcate the line ends and angle vertexes, were devised to control for the contour interaction effect (Carlson, Moeller, \& Anderson, 1984; Coren, 1970a, 1970b; Girgus, Coren, \& Fraenkel, 1975; Wenderoth \& Wade, 1981). Also, figures have been presented stereoscopically (Day, 1961; Schiller \& Weiner, 1962) or as cyclopean stimuli (Coren \& Porac, 1984; Julesz, 1971) to eliminate contour interactions on one retinal surface. Researchers usually report a reduction in illusion magnitude for these stimulus variants relative to the standard configurations and have concluded that the elimination of the contour interaction component accounts for the diminished illusion strength. This approach has one major weakness, however. For the desired effects to be studied, the illusion configuration itself must be altered. Since illusions arise because of mechanisms triggered by specific pattern elements, the mechanisms operating in such modified configurations may be different from those that are the major determinants of illusion strength in standard forms of the configuration. This suggests that generalizations about the magnitude of the contribution of contour interactions to illusion strength that are based upon data from such modified figures may be somewhat suspect.

Fortunately, there is an experimental technique that varies the magnitude of inhibitory interactions without modification to the illusion pattern itself. When the retina is exposed to a flash of light, there is an initial onset transient of increased neural activity (see Figure 3). These neural response transients are accompanied by stronger inhibition of laterally adjacent cells (Ratliff, 1965; Rat- liff, Knight, Toyoda, \& Hartline, 1967). Flickering stimuli at an appropriate frequency should cause summation of these onset transients, and hence, theoretically, should produce an increase in the lateral inhibition evoked by the stimulus (Ratliff, Knight, \& Graham, 1969; Walters \& Harwerth, 1978). While flickering a stimulus does seem to provide a means for increasing lateral inhibitory effects without altering the pattern elements, simple squarewave flicker is not the optimal stimulus to do this. As can be seen from Figure 3, in addition to the onset transients that occur with increased neural activity (which we would like to sum by selecting a flicker rate in which they overlap temporally), there is also a negative offset transient that occurs with decreased activity. Summation of the total neural response would cause some overlapping of the onset transients and the offset transients of successively flashed stimuli, hence limiting the degree to which the lateral inhibition may be increased by this technique. This problem can be overcome by utilizing an intermittent-light source that does not generate a square wave, but rather has a sharp onset (to maximize the onset transients) and gradual or ramp offset (to minimize the offset transients).

The arguments presented above suggest a method of measuring the relative contribution of lateral inhibition to any given illusion.

To see how this procedure should work in a specific situation, consider an illusory distortion, such as the Müller-Lyer, which is presumed to have a lateral inhibitory component on the basis of data from other techniques. If this illusion configuration is now presented under an appropriate intermittent illumination, illusion magnitude
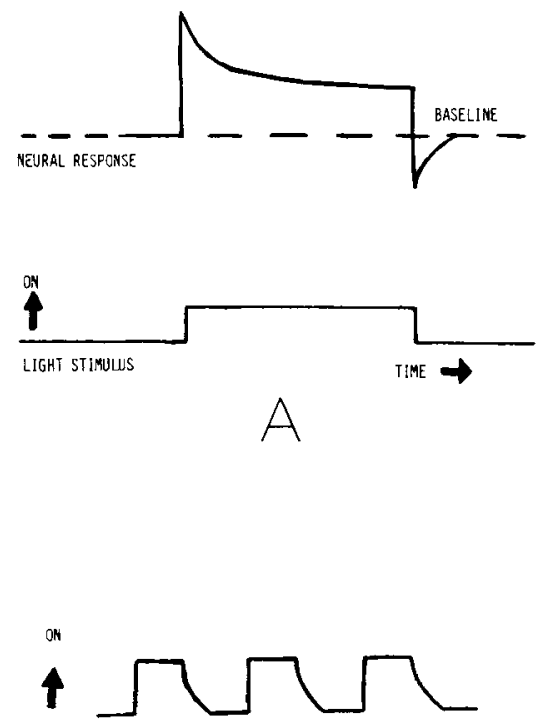

Figure 3. (A) The neural transient resulting from the sharp onset and offset of a light stimulus. (B) The actual pattern of the intermittent stimulus, with sharp onset and tapered offset, used to illuminate the illusion figures in the present experiments. 
should be increased at some optimal flicker rate where onset transients are maximally summed. If, on the other hand, we selected a configuration in which lateral inhibition does not contribute to the perceptual distortion, the illusion magnitude should remain constant regardless of the flicker rate under which it is viewed. The degree by which the illusion magnitude is increased by presentation under intermittent illumination could thus serve as an index of the relative contribution of this mechanism to the final illusion. The following experiments were conducted to test these hypotheses in the context of variants of the Müller-Lyer illusion.

\section{EXPERIMENT 1}

As we discussed above, if presentation of a configuration under intermittent illumination increases the magnitude of lateral inhibitory effects at specific flicker rates, and if lateral inhibition contributes to illusion formation, the magnitude of the illusion should increase at these flicker rates. If we use a figural variant that is presumed to be free of lateral inhibitory contributions, illusion magnitude should be independent of flicker rate. We tested these hypotheses with the standard Brentano form of the Müller-Lyer illusion (Figure 4A), assumed to have a large lateral inhibitory component by virtue of the converging and intersecting line elements contained within it (see Coren \& Girgus, 1978a; Coren et al., 1984), and the dot form of the illusion (Coren, 1970a) in which lateral inhibitory effects have been minimized by removal of the line elements (Figure 4B).

\section{Method}

Subjects. Thirty undergraduate students at the University of British Columbia served as subjects. All had normal or corrected-tonormal vision and were naive as to the purpose of the experiment.

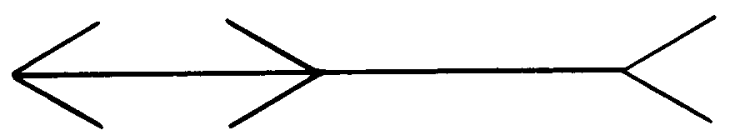

$$
\text { A }
$$

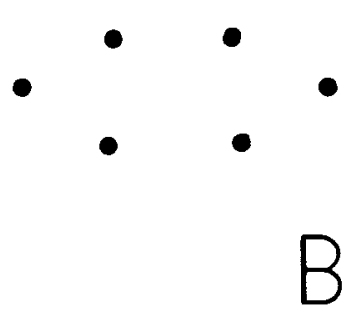

Figure 4. The Brentano form of the Müller-Lyer illusion in line (A) and dot form (B).
Stimuli and Apparatus. We used the Brentano form of the Müller-Lyer illusion in line (Figure 4A) and dot form (Figure 4B) Stimuli were constructed in a tongue and groove arrangement, in which the apparently shorter portion was fixed while the apparently longer portion was adjustable. The fixed portion of each figure was $80 \mathrm{~mm}$ in length. Each wing was $20 \mathrm{~mm}$ and formed a $30^{\circ}$ angle with the horizontal shaft. The figures were constructed with 2 -mm white lines or 2 -mm-diam dots ( $81 \%$ reflectance) on a black background ( $5 \%$ reflectance). A practice stimulus with the same dimensions but with wings at $90^{\circ}$ to the shaft was also used.

As we discussed above, square-wave flicker will not accomplish the desired increased inhibitory effect because onset and offset transients will sum, hence cancelling out the desired augmentation of neural activity (see Figure 3A). A fluorescent tube, whose onset flash was generated by a hot cathode system, was used to provide an intermittent-light source that did not generate a square wave but, rather, had a sharp onset, to maximize the onset transient, and gradual or ramp offset, to minimize the offset transient. This stimulus-generation system, used in some tachistoscopes, provided a pattern of illumination similar to that shown in Figure 3B. With this type of intermittent light, there should be a flicker rate at which the onset transients summate, increasing the lateral inhibitory effects generated by a visual pattern.

Our flickering light source consisted of four hot cathode fluorescent tubes driven by a Gerbrands tachistoscope driver and timer. Their illumination was $72 \mathrm{~cd} / \mathrm{m}^{2}$. Stimulus onset was $0.1 \mathrm{msec}$ from initiation. At this stimulus intensity, and given the resting voltage applied to the cathode during the off-cycle, the stimulus falloff at the termination of a flash was in the shape shown in Figure 3B. The disappearance time was approximately $14 \mathrm{msec}$. The figures were viewed at a distance of approximately $45 \mathrm{~cm}$ with light sources located $30 \mathrm{~cm}$ above them.

Procedure. The line and dot forms of the Müller-Lyer were presented under six different exposure conditions, continuous or intermittent illumination with cycles of $100,200,300,400$, and $500 \mathrm{msec}$, with a $50 \%$ duty cycle for the illumination. Following two settings with the practice figure, measurements were taken for each of the figures and exposure conditions in randomized blocks of two settings. Each stimulus and exposure block was presented twice at random times during the session, for a total of four settings per condition. Starting points were ordered randomly within the blocks.

\section{Results and Discussion}

Illusion magnitude was computed for all subjects under each stimulus and illumination condition by subtracting each subjective setting from the veridical extent $(80 \mathrm{~mm})$ of the stationary portion of the stimulus figure. The results of Experiment 1 are shown in Figure 5, which plots these illusion-magnitude scores for both the line and dot Müller-Lyer forms as a function of the flicker rate. The magnitude of the Brentano (line) form of the illusion is greater than that of the dot form. This difference is statistically significant $[F(1,29)=32.37, p<.01]$, and thus replicates previous findings using these configurations (Girgus, Coren, \& Horowitz, 1973). The absence of the lateral inhibitory contribution to the magnitude of the distortion in the dot form is, of course, thought to be responsible for this difference in illusion strength (Coren, 1970a; Girgus, Coren, Durant, \& Porac, 1975; Girgus, Coren, \& Fraenkel, 1975).

Figure 5 also shows a clear increase in illusion magnitude for intermittent illumination, relative to continuous 


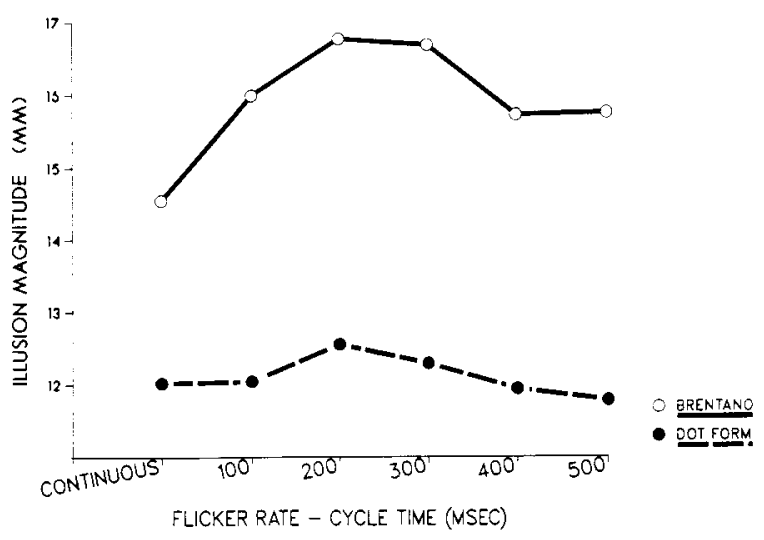

Figure 5. The results of Experiment 1, with illusion magnitude plotted against the flicker rate. The solid line represents the data from the Brentano (line) form of the Muiller-Lyer illusion, while the broken line represents the results from the dot form of the illusion.

illumination. Illusion magnitude reaches its peak at a cycle length of $200 \mathrm{msec}(5 \mathrm{~Hz})$, diminishing for exposure cycles that are longer or shorter. An analysis of variance indicated that the rate of flicker had a significant effect on illusion magnitude $[F(5,145)=4.02, p<.01]$, and a trend analysis indicated that the quadratic component, visible in Figure 5 as an inverted U-shaped function, was also statistically significant $[F(1,145)=14.65, p<.01]$. This result is consistent with the suggestion that summing the onset transients augments the lateral inhibitory contribution for intermediate flicker rates. The results from the dot form of the Müller-Lyer did not show this effect. The effect of flicker on illusion magnitude was not significant for the dot configuration $[F(5,145)=0.39]$, nor was the quadratic component $[F(1,145)=1.14]$. This result is also consistent with the assumption that lateral inhibition does not make a significant contribution to the dot form of the illusion.

As we noted in the preceding paragraph, the largest increase in the line-form illusion magnitude occurs at a cycle duration of $200 \mathrm{msec}$. This $5-\mathrm{Hz}$ flicker rate is similar to that which Ratliff et al. (1967) found to be optimal for the augmentation of lateral inhibitory effects. At this cycle rate, the increase in illusion magnitude for the configuration made up of lines is approximately $14 \%$ over that observed under continuous illumination conditions. This difference in illusion magnitude as a function of illumination conditions is large enough to suggest that the technique of presenting illusion stimuli under intermittent illumination can be used to measure the relative contribution of lateral inhibition in various illusion configurations.

\section{EXPERIMENT 2}

Experiment 2 explored whether or not the flicker presentation method would be useful in ascertaining the relative role of lateral inhibition in variants of the same illusion configuration. We systematically altered the
Müller-Lyer form and constructed a series of figural variants that differed in the presumed amount of lateral inhibitory contribution to the final distortion. Specifically, since converging line elements of close spatial proximity are argued to be the critical stimulus component for lateral inhibitory interactions, it has been alleged that more acute wing angles provide a greater opportunity for the operation of lateral inhibitory interactions. Some researchers suggest that this is why decreases in the size of the angle between the wings leads to greater illusion (e.g., Coren \& Girgus, 1978a). If the above interpretation is correct, and if the technique we had explored was sensitive enough to detect differences in the relative contribution of lateral inhibition to illusion variants, we should find that the increase in illusion magnitude under intermittent illumination would be greatest when the angle between the wings was small.

\section{Method}

Stimuli and Apparatus. We used the same light source as in Experiment 1 but reduced the variations in intermittency rate to only two exposure conditions. Since flicker based upon a 200 -msec cycle time with $50 \%$ duty cycle $(5 \mathrm{~Hz})$ produced the maximum effect in Experiment 1, it was contrasted against continuous illumination. Four Brentano forms of the Müller-Lyer, consisting of solid lines and made of the same materials and with the same stimulus dimensions as described for the line stimuli in the first study, were employed. The four variants of the illusion differed only in the angles between the wings, assuming values of $15^{\circ}, 30^{\circ}, 45^{\circ}$, and $60^{\circ}$ from the horizontal shaft, respectively. We used a $90^{\circ}$ practice stimulus, as in the previous experiment.

Subjects. Forty undergraduate student volunteers served as subjects. All had normal or corrected-to-normal vision and were naive as to the purpose of the experiment.

Procedure. The four illusion forms, differing in wing angle, were presented under either continuous or intermittent (200-msec cycle) illumination. Following two settings on the $90^{\circ}$ practice figure, measurements of illusion magnitude were made for all combinations of figure and exposure condition, in randomized blocks of two settings. Each stimulus and exposure block was presented twice at random times during the session, for a total of four settings per condition. Starting points were ordered randomly within the blocks.

\section{Results and Discussion}

We computed illusion-magnitude scores for each subject as described in Experiment 1, and the mean results as a function of wing-angle and illumination condition are shown in Figure 6. Our findings show the expected increase in illusion magnitude for more acute angles for both illumination conditions. This main effect was statistically significant $[F(3,117)=34.12, p<.01]$ and replicates earlier findings (Coren, 1986; Erlebacher \& Sekuler, 1969; Restle \& Decker, 1977). As expected from the results of Experiment 1, there was also a main effect of exposure condition, with intermittent stimulation producing stronger illusion effects than continuous stimulation $[F(1,39)=14.52, p<.01]$; however, this effect was not uniform across all wing angles.

As indicated above, our predictions were based upon the presumption that there were larger lateral inhibitory effects in the Müller-Lyer forms with acute wing angles. If, as suggested by Experiment 1, there is an augmenta- 


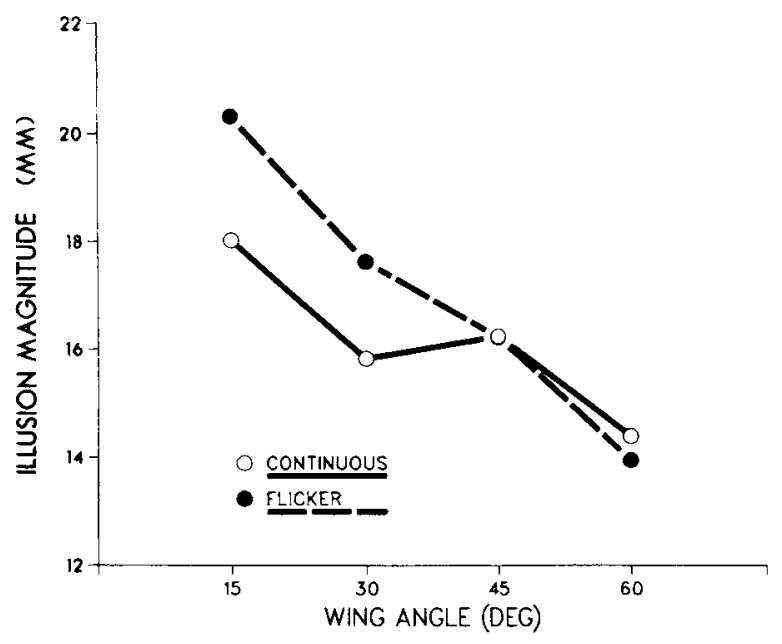

Figure 6. The data from Experiment 2 with the magnitude of the Müller-Lyer illusion plotted against wing angle for both continuous illumination (solid line) and intermittent illumination (broken line).

tion of illusion magnitude under intermittent illumination because the lateral inhibitory transients summate, these combined effects should produce a statistical interaction between angle size and exposure condition, a result observed in our data $[F(3,117)=8.58, p<.01]$. There was little difference in illusion magnitude as a function of continuous versus intermittent illumination for the wideangle stimuli $\left(45^{\circ}\right.$ and $\left.60^{\circ}\right)$; however, the difference emerged for the small-angle $\left(15^{\circ}\right.$ and $\left.30^{\circ}\right)$ figures, where there was an increased illusion magnitude under intermittent stimulation. This result suggests a nonmonotonic relationship between lateral inhibitory contributions to the magnitude of the Müller-Lyer illusion as a function of angle size. Illusion arrays with angles larger than $45^{\circ}$ may not evoke lateral inhibitory mechanisms to the extent found in illusion variants with small angles.

\section{EXPERIMENT 3}

The theoretical rationale behind Experiments 1 and 2 depends upon the presumption that intermittent illumination of the type used here can sum lateral inhibitory transients. Although the results of the two experiments seem to confirm this assumption, it might be useful to demonstrate that this procedure has the expected effect upon a phenomenon traditionally held to be due to lateral inhibition. For this purpose, we decided to test subjects on a standard simultaneous brightness-contrast stimulus array under continuous versus intermittent illumination.

\section{Method}

Subjects. There were 10 subjects in this experiment. All had normal or corrected-to-normal vision. Three were skilled in psychophysical judgments. All subjects were naive as to the purpose of the experiment.

Stimuli and Apparatus. The same light source used in the previous experiments was used with two exposure conditions, as in Ex- periment 2 . These were a continuous illumination and a $200-\mathrm{msec}$ duty cycle $(5 \mathrm{~Hz})$ intermittent-illumination condition.

Stimuli were constructed from matte surfaced papers, and consisted of a middle gray ( $24 \%$ reflectance, approximately Munsell N 5.5) either on a white ( $88 \%$ reflectance, Munsell N 9.5 ) or a black (3.4\% reflectance, Munsell N 2) background. At a viewing distance of $40 \mathrm{~cm}$, the background stimuli produced a square image, $10^{\circ}$ of arc on each side, while the test gray stimulus was centered on the background and was $2.5^{\circ}$ square. A larger square sample of the gray paper $\left(14^{\circ}\right.$ on each side) was continuously visible $28^{\circ}$ to the right of the test stimulus. This stimulus, which served as the comparison, was always visible and was presented under continuous illumination.

Procedure. Brightness measurements were taken via a magnitude estimation procedure. The continuously illuminated gray comparison stimulus served as the modulus and was assigned a magnitude of 100 . All other brightness levels were to be judged relative to this modulus.

Subjects made 10 judgments of the brightness of each gray on the black or white background under both intermittent and continuous illumination. Stimuli and exposure conditions were sequenced randomly.

\section{Results and Discussion}

If intermittent illumination of the form used here does lead to a summation of lateral inhibitory transients as we have suggested, this should manifest itself as an increase in brightness contrast under the flickering stimulus. To assess this, the difference between the mean magnitude estimations of the gray on black and the gray on white were taken under both continuous and intermittent illumination. This difference, of course, is simply a composite measure of the amount of simultaneous brightness contrast present under each exposure condition.

The magnitude of brightness contrast manifested in these stimuli amounts to 16.1 for continuous illumination $[t(9)=2.74, p<.05]$ and 44.7 under the $5-\mathrm{Hz}$ intermittent stimulation $[t(9)=3.43, p<.01]$. The magnitude of the simultaneous contrast is significantly greater under flicker than under continuous illumination $[t(9)=$ $3.52, p<.01]$. To the extent that brightness contrast is due to lateral inhibitory interactions, this seems to confirm that the intermittent stimulus presentations used in the illusion studies is an effective means of summing the stimulus onset transients, and hence increasing the extent of the lateral inhibitory interactions manifest under these viewing conditions. It thus seems more likely that the variations in illusion magnitude observed in Experiments 1 and 2 were actually due to variations in the contribution of lateral inhibition.

\section{GENERAL DISCUSSION}

Experiments 1 and 2 demonstrated a technique that assesses the contribution of lateral inhibitory interactions to the final magnitude of the Müller-Lyer illusion. We proposed that intermittent illumination of illusion stimuli causes summation of onset transients associated with lateral inhibition, thus increasing illusion magnitude; this seems to be indirectly confirmed by the finding in Experiment 3 that simultaneous brightness contrast is aug- 
mented under conditions of flicker. In Experiment 1 the illusion magnitude of a standard line form of the MüllerLyer figure reached a peak at specific flicker rates; however, measurements on a dot form of the illusion, which minimizes the opportunity for lateral interactions, remained relatively constant across all flicker rates tested.

In Experiment 2, we tested the sensitivity of the flicker technique. We varied the wing-shaft angle size in the Müller-Lyer, because increases in illusion strength observed with small-angle figures are thought to be the result of the increased contribution of lateral interactions. Müller-Lyer variants with the most acute angles showed the largest augmentation in illusion strength under intermittent stimulation, as expected. The lateral inhibitory contribution, as assessed by increments in illusion magnitude, was apparent in small-angle configurations but did not seem to contribute much to the distortion for wideangle ( $45^{\circ}$ and larger) arrays.

The results of these two experiments have both theoretical and methodological implications. Theoretically, they provide another demonstration of the contribution of lateral retinal interactions to the formation of the Müller-Lyer illusion. Methodologically, they provide a convenient procedure for assessing the relative contribution of lateral inhibitory effects to illusion formation. The increase in illusion strength is readily measurable for optimal configurations under the appropriate flicker rate. Thus, if we compare the illusion strength in the most acute-angled figures under flicker presentation conditions with that observed in the widest angled figures under continuous illumination (see Figure 6), we find an approximate 6-mm difference in measured illusion magnitude between these two conditions. This difference constitutes a $41 \%$ increase in illusion strength under conditions that are optimal for lateral inhibitory involvement.

On the other hand, there are some limitations to the technique that we have been describing. The major one is that we can measure only the relative, rather than the absolute, contribution of lateral neural interactions to the illusion. Thus, although we can expect that the greater the initial contribution of lateral inhibition to illusion formation, the greater the increase we should observe in illusion magnitude under intermittent illumination, we cannot, at present, extrapolate back from these results to determine the initial percentage of the illusion due to this mechanism. However, we should be able to rank-order illusion configurations on the basis of the relative contribution of lateral inhibition to their total distortion, and to determine which configurations do not owe their existence to such neural interactions.

In summary, then, the present findings indicate that there is a large and measurable contribution of lateral inhibition to several variants of the Müller-Lyer illusion. Furthermore, these data suggest that presentation of illusion configurations under the appropriate form of intermittent stimulation may provide a useful means by which to assess the relative contribution of lateral inhibition to the magnitude of other illusory distortions.

\section{REFERENCES}

Carlson, C. R., Moeller, J. R., \& Anderson, C H. (1984). Visual illusions without low spatial frequencies. Vision Research, 24, 1407-1413.

Carpenter, R. H. S., \& Blakemore, C. (1973). Interaction between orientation in human vision. Experimental Brain Research, 18, 287-303.

COREN, S. (1969). The influence of optical aberrations on the magnitude of the Poggendorf illusion. Perception \& Psychophysics, 6, 185-186.

COREN, S. (1970a). Lateral inhibition and geometric illusions. Quarterly Journal of Experimental Psychology, 22, 274-278.

COREN, S. (1970b). Lateral inhibition and the Wundt-Hering illusion. Psychonomic Science, 18, 341.

Coren, S. (1986). An efferent component in the visual perception of direction and extent. Psychological Review, 93, 391-410.

Coren, S., \& Girgus, J. S. (1972). Differentiation and decrement in the Mueller-Lyer illusion. Perception \& Psychophysics, 12, 466-470.

Coren, S., \& Girgus, J. S. (1977). Illusion constancies. In W. Epstein (Ed.), Stability and constancy in visual perception: Mechanisms and processes (pp.255-283). New York: Wiley.

Coren, S., \& Girgus, J. S. (1978a). Seeing is deceiving: The psychology of visual illusions. Hillsdale, NJ: Erlbaum.

Coren, S., \& Girgus, J. S. (1978b). Visual illusions. In R. Held, H. Leibowitz, \& H.-L. Teuber (Eds.), Handbook of sensory physiology: Vol. VIII. Perception (pp. 549-568). Berlin: Springer-Verlag.

Coren, S., Girgus, J. S., \& SChiano, D. (1986). Is adaptation of orientation-specific cortical cells a possible explanation of illusion decrement? Bulletin of the Psychonomic Society, 24, 207-210.

Coren, S., \& Miller, J. (1974). Size contrast as a function of figural similarity. Perception \& Psychophysics, 16, 355-357.

Coren, S., \& PORAC, C. (1978). Iris pigmentation and visual-geometric illusions. Perception, 7, 473-478.

Coren, S., Porac, C. (1983). The creation and reversal of the Mueller-Lyer illusion through attentional manipulation. Perception, 12, 49-54.

Coren, S., \& Porac, C. (1984). Structural and cognitive components in the Müller-Lyer illusion assessed via cyclopean presentation. Perception \& Psychophysics, 35, 313-318.

Coren, S., Porac, C., \& WARd, L. M. (1984). Sensation and perception (2nd ed.). Orlando, FL: Academic Press.

CoREN, S., \& WARD, L. M. (1979). Levels of processing in visual illusions: The combination and interaction of distortion-producing mechanisms. Journal of Experimental Psychology: Human Perception \& Performance, 5, 324-335.

Coren, S., Ward, L. M., Porac, C., Fraser, R. (1978). The effect of optical blur on visual-geometric illusions. Bulletin of the Psychonomic Society, 11, 390-392.

DAY, R. H. (1961). On the stereoscopic observation of geometric illusion. Perceptual \& Motor Skills, 13, 247-258.

Erlebacher, A., \& Sekuler, R. (1969). Explanation of the MuellerLyer illusion: Confusion theory examined. Journal of Experimental Psychology, 80, 462-467.

Gillam, B. (1971). A depth processing theory of the Poggendorf illusion. Perception \& Psychophysics, 10, 211-216.

Gillam, B. (1980). Geometrical illusions. Scientific American, 242, $102-111$.

Gillam, B., \& Chambers, D. (1985). Size and position are incongruous: Measurements on the Müller-Lyer figure. Perception \& Psychophysics, 37, 549-556.

GirguS, J. S. , \& CoREN, S. (1982). Assimilation and contrast illusions: Differences in plasticity. Perception \& Psychophysics, 32, 555-561. 
Girgus, J. S., Coren, S., Durant, M., \& Porac, C. (1975). The assessment of components involved in illusion formation using a longterm decrement procedure. Perception \& Psychophysics, 18, 144-148.

Girgus, J. S., Coren, S., \& FaEnkel, R. (1975). Levels of perceptual processing in the development of visual illusions. Developmental Psychology, 11, 268-273.

Girgus, J. S., Coren, S., \& Horowitz, L. (1973). Peripheral and central components in variants of the Mueller-Lyer illusion. Perception \& Psychophysics, 13, 157-160.

Goryo, K., Robinson, J. O., \& Wilson, J. A. (1984). Selective looking and the Müller-Lyer illusion: The effect of changes in the focus of attention of the Müller-Lyer illusion. Perception, 13, 647-654.

Gregory, R. L. (1968). Visual illusions. Scientific American, 219, 66-76.

JORDON, K., \& UHLARIK, J. (1986). Length contrast in the Müller-Lyer figure: Functional equivalence of temporal and spatial separtion. Perception \& Psychophysics, 39, 267-274.

Julesz, B. (1971). Foundations of cyclopean perception. Chicago: Chicago University Press.

Mack, A., Heuer, F., Villardi, K., Chambers, D. (1985). The dissociation of position and extent in Müller-Lyer figures. Perception \& Psychophysics, 37, 335-344.

Massaro, D. W., \& Anderson, N. H. (1971). Judgmental model of the Ebbinghaus illusion. Joumal of Experimental Psychology, 81, 147-151.

Pressey, A. W. (1974). Evidence for the role of attentive fields in the perception of illusions. Quarterly Journal of Experimental Psychology, 26, 464-471.

RATLIFF, F. (1965). Mach bands: Quantitative studies on neural networks in the retina. New York: Holden-Day.

RatlifF, F., Knight, B. E., \& Graham, N. (1969). On tuning and amplification by lateral inhibition. Proceedings of the National Academy of Science, 62, 733-740.

Ratliff, F., Knight, B. W., Toyoda, J., Hartune, H. K. (1967). Enhancement of flicker by lateral inhibition. Science, 158, 392-393.
Restle, F., \& Decker, J. (1977). Size of the Mueller-Lyer illusion as a function of its dimensions: Theory and data. Perception \& Psychophysics, 21, 489-503.

SCHILler, P., \& WeINER, M. (1\%62). Binocular and stereoscopic viewing of geometric illusions. Perceptual \& Motor Skills, 13, 739-747

UTtaL, W. (1981). A taxonomy of visual processes Hillsdale, NJ Erlbaum.

WaLlaCe, G. K. (1975). The effect of contrast on the Zöllner illusion. Vision Research, 15, 963-966

WALTERS, J. W., HARWERTH, R. S (1978). The mechanism of brightness enhancement. Vision Research, 18, 777-779.

WARD, L. M , COREN, S. (1976). The effect of optically induced blur on the magnitude of the Mueller-Lyer illusion Bulletin of the Psychonomic Society, 7, 483-484.

Ward, L. M., Porac, C., Coren, S., \& Girgus, J. S. (1977). The case of misapplied constancy scaling: Depth associations elicited by illusion configurations. American Journal of Psychology, 90, 609-620.

WARRFN, R. M., BASHFord, J. A. (1977). Müller-Lyer illusions: Their origin in processes facilitating object recognition. Perception, 6, 615-626.

Weintraub, D., \& Schneck, M. K (1986). Fragments of Delboeuf and Ebbinghaus illusions: Contour/context explorations of misjudged circle size. Perception \& Psychophysics, 40, 147-158.

Wenderoth, P., Beh, H., \& White, D. (1978). Perceptual distortion of an oblique line in the presence of an abutting vertical line. Vision Research, 18, 923-930.

Wenderoth, P., O'Connor, T., \& Johnson, M. (1986). The tilt illusion as a function of the relative and absolute lengths of test and inducing lines. Perception \& Psychophysics, 39, 339-345.

WeNDEROTH, P., \& WAD, N. (1981). An investigation of the line and the dot forms of the Mueller-Lyer and Poggendorf illusions. Quarterly Journal of Experimental Psychology, 33, 77-85.

(Manuscript received May 19, 1987; revision accepted for publication November $25,1987$. 